\title{
Online engagement from the grassroots: Reflecting on over a decade of ePetitioning experience in Europe and the UK
}

\author{
Panagiotis Panagiotopoulos and Tony Elliman \\ Department of Information Systems and Computing \\ Brunel University, West London, UB8 3PH, UK \\ \{Panagiotis.Panagiotopoulos, Tony.Elliman\}@brunel.ac.uk
}

Book chapter to appear at:

Empowering Open and Collaborative Governance

Technologies and Methods for Online Citizen Engagement in Public Policy Making

Editors: Yiannis Charalabidis and Sotirios Koussouris

Publisher Springer, due March 2012, available at:

http://www.springer.com/computer/information+systems+and+applications/book/978-3-642$\underline{27218-9}$

\begin{abstract}
Extensive debate on Internet and formal politics has concentrated on whether authorities should focus their efforts on high-volume activities such petitioning or crowdsourcing. Those engagement tools seem to be consistent with the ambition of many networked citizens to influence policy making through ad hoc and mostly single-issue movements. Therefore, certain interesting questions emerge: can authorities organise their engagement activities to respond and act upon this call? Can citizens indeed influence policy making in a few clicks? This chapter draws together material from different uses of ePetitioning tools in Europe, mainly focusing on the integrated UK experience at national and local level. The analysis suggests that those initiatives can provide valuable feedback to authorities and be effectively complemented by other forms of deeper engagement. Yet, political organisations should pay close attention on how the public views such exercises and be prepared to support participants in different ways and on a regular basis.
\end{abstract}




\section{Introduction}

Both citizens and public institutions have seen web technologies and their widespread adoption as a means to enfranchise political participation activities. In doing so, networked citizens have attempted to transcend the boundaries of existing policy making and put pressure on public bodies to recognise and respond to their bottom-up involvement efforts (Dutton, Eynon 2009). Scenarios describing the future of public engagement have even introduced concepts such as self-service governance where empowered community groups will organise around their own topics of interest and directly determine government actions (Misuraca et al. 2011). For example, the Big Society agenda of the new British government elected in 2010 seems to be an illustration of such community empowerment plans (Cabinet Office 2011).

Nevertheless, the ambition of citizens to determine policy implies overturning the historical development of representative democracy. Despite the few exceptions, such as California's ballot proposition or the Swiss referendum system, citizens' legitimacy to set the public agenda seems to be either openly contested or silently resisted. Instead, authorities select engagement activities aimed at promoting massive dissemination of public material or targeted involvement in a manageable way (Saebo et al. 2008). Even when it comes to high-volume tools such as social networking groups, petitioning or crowdsourcing, it is actually still the authority that controls the process and decides on the actual influence achieved. However, such forms of participation don't seem to meet with unqualified public approval. As Miller (2009, p.165) notes: "most people prefer to get involved in single-issue politics, ignoring institutional agendas that often seem alien, time-consuming and irrelevant."

Criticism of citizen participation in high-volume and low-commitment actions, especially by elected representatives, has sought to undermine them with pejorative terms like "clicktivism" (Karpf 2010), "point and click democracy" (Dutton 2009) or even political graffiti (Miller 2009). Hence, there seems to be a misalignment between: (1) citizens' efforts to influence policy making through online ad hoc movements and (2) authorities' claims to recognise and act upon those bottom-up initiatives. Since this problematic alignment seem to be one of the main elements limiting the impact of ICTs in governance, an interesting question emerges:

- Can high volume activities be organised in ways that will widen the scope of traditional politics and enable citizens to achieve engagement influence?

The chapter addresses this question by focusing on ePetitions which is the most developed experience with high-volume tools by authorities at different levels: parliaments, national and local governments. In Europe, and particularly in the UK, there is long history of grassroots petitioning initiatives as a valid political activity long before experimentations with the online part of this process. Experiences with different uses of ePetitioning systems during the last decade are drawn together in 
section 2. Going on to synthesise and compare their different aspects in section 3 provides certain useful insights on high-volume engagement.

\section{Online petitioning in Europe and the UK}

The concept behind petitioning is simple: a group of citizens place a single issue request before an authority or organisation asking it to undertake or impede certain actions or public policies. The weight of public sentiment behind the request is indicated simply by the number of signatories to the petition. The effects of moving from traditional petitioning to online technology are significant: the Internet centralises and accelerates the process while offering a wide range of support mechanisms. Placing petitions on a centrally visible website decreases the requirement of organising massive dissemination activities by a group of dedicated volunteers. This enables individuals to create their own petitions and promote them through conventional Internet tools such as mailing lists, social networking groups or newsletters.

Inevitably, online petitioning also raises issues of authentication since the identity of petitioners cannot be fully verified; in most cases, protection is provided only against massive frauds. In the UK, even with paper petitioning, full identification has not been a barrier. For example, in many local authorities, it is achieved by verifying a random number of signatures up to the required threshold for a petition to be officially considered.

Despite such limitations, according to the Oxford Internet Survey (Dutton, Helsper 2007, Dutton et al. 2009), petitions are the most popular online civic participation activity in the UK. As an easy and convenient form of political engagement, ePetitioning has been very popular amongst individual Internet users, NGOs and even commercial organisations. For example, international political groups are using petitioning tools as part of their mass e-mail campaigns (Karpf 2010, Shulman 2009). Such mobilisation efforts belong to the sphere of digital activism and protesting which is arguably a completely different set of activities from participation organised by political institutions (Garrett 2006).

When it comes to institutional policy making, ePetitions seem to be one of the most important areas and they are gaining maturity even at the regulatory level (see section 2.3). As Lindner and Riehm (2011) explain, ePetitioning clearly seems to be at the forefront of official, all-inclusive and nonexperimental eParticipation opportunities being made available to the public. The following review of current experiences with ePetitioning tools progresses from Parliaments to national and local governments. 


\subsection{Petitioning the parliament}

Many parliaments have been historically accepting paper petitions by citizens or groups of citizens who wish to influence their agenda. The types of petitions and the way those petitions are handled varies greatly (e.g. Lindner, Riehm 2009). The Scottish Parliament (SP) was the first political institution to implement an ePetitioning initiative. Since its institutional origins in 1999, the SP has been designed to be compatible with web technologies in different activities (e.g. interactive forums, webcasting) (Seaton 2005). As informed by Seaton (2005, p.336), ePetitions "have encouraged participation in real politics by people who might otherwise have felt that there was no opportunity to participate".

In March 2000, the ePetitioner system, developed by Napier University, was open for the public in a pioneer moment for the emerging concept of eDemocracy. Macintosh et al. (2002) illustrate the details of this system and the ways in which the SP handles petitions though a dedicated Public Petitions Committee which considers submitted petitions and consults on possible actions. The SP puts no restrictions on minimum numbers of signatures for a petition to be considered (threshold), has an embedded discussion forum and also accepts signatures from non-Scottish citizens. The system was further developed and formally re-launched in 2004. The official website lists about 1400 open and closed petitions (Scottish Parliament 2011). It also informs on the international interest of this initiative and a number of other authorities which have sought advice from the SP.

One of the first to do so was the German federal parliament. In pilot operation since 2005 and at regular service from 2007, the German Bundestag has a well-developed experience with ePetitions (Lindner, Riehm 2009, 2011, Jungherr, Jürgens 2010). The German parliament receives paper and online petitions and discusses in public those supported by a minimum of 50,000 signatures regardless of the submission channel.

Lindner and Riehm (2011) provide a detailed description of how the ePetitioning concept evolved in the German parliament, for example in terms of technical and organisational barriers. The introduction of ePetitions came along with procedural innovations. Before 2005, the parliamentary petition process was not public. Since 2005, ePetitions of general political interest are accepted as public. The website was associated with a significant increase in the number of petitions until 2009, after which only the number of signatures increased considerably. Interestingly, since 2006, the percentage of petitions made electronic, as well as the use of discussion forums has increased, but the acceptance rate of ePetitions has decreased. Acceptance is decided by an office of 80 full-time staff which seems to hold considerable power over the process. So far, popular ePetitions have received more than 100,000 signatures; for example, the most popular was the one opposing legislation related to Internet regulation (134,000 signatures). In the period 2006-2009, the petitions committee held 11 public meetings in which 81 petitions were discussed.

Another European parliamentary institution to implement an ePetitioning initiative, since 2008, is the Welsh Assembly which was created in 1998. According to the official report from the Petitions 
Committee, in the period 2008-2011, 215 petitions were discussed in 64 meetings; 95 of those petitions were submitted online (National Assembly for Wales 2011). As with the Scottish Parliament, petitions can be submitted from outside Wales. An interesting point is that only $56 \%$ of petitions were initiated by individual citizens; the rest $44 \%$ came from organisations or groups. The report explores some examples of petitions received and mentions certain negative points brought up by petitioners; for example, the process being too slow, not all petitioners being invited for public hearings and no significant impact achieved in some cases.

Furthermore, although not using ePetitions yet, some interesting information about the British Parliament comes from Miller's (2009) illuminating article. The description of Westminster's internal debates illustrates the dilemmas involved when ICTs attempt to merge with formal political processes. In this case, the process was petitioning via a member of the parliament. At the first level, the parliament had to decide whether it would replicate or take over the popular but controversial UK government's system (see next section). Next, it had to consider a petitioning process that would be meaningful both for the public and parliamentarians and also compatible with the parliament structures and capacities. Barriers to introducing the system could be summarised as: public distrust in procedural fairness, populist petitions gaining wide media attention, high running cost, significant workload increase, considerable response delays and negative opinions by parliamentarians.

An interesting attempt to transfer the ePetitioning idea at the European Parliament is the EuroPetition project (Cruickshank, Smith 2011a, 2011b). This cross-border and multi-lingual initiative included a mixture of local authorities in Europe with various experiences: from the UK to Italy, the Netherlands, Sweden and Spain where the concept was new but generated interest. In total, 63 petitions were signed by almost 1400 users in different topics and useful recommendations were drawn on how to make the initiative sustainable at European level.

Outside Europe, online petitions have been used by the Queensland Parliament in Australia since 2002 (Lindner, Riehm 2009). As currently with the British Parliament, petitions in either paper or electronic form can only be introduced by an elected representative. An important difference with other parliament petitions is that responses are officially generated by responsible ministers within 30 days and published on the website for both online and paper petitions.

Finally, in addition to our knowledge on how parliaments explored the ePetitioning idea, certain evaluation studies have uncovered interesting facts about citizens' responses and patterns of use:

- Carman (2010) analysed the results of a postal survey which in June 2006 was sent to 722 Scottish Parliament petitioners and completed by approximately half of them (we are not sure if they are online or paper petitioners). The results show that petitioners had high expectations of the process with about $90 \%$ anticipating that their petition would be handled "fairly". However, about half of those actually thought that their petition was indeed handled "fairly" and only about 
$17 \%$ were generally satisfied with the outcome. The statistical analysis also revealed that the evaluation of procedural fairness clearly influences trust in the Scottish political system as a whole.

- Jungherr and Jürgens (2010) analysed a large dataset of public ePetitions to the German Parliament between 2008 and 2010 which included 886 petitions from about 495,000 users. Only 4 of those petitions passed the 50,000 threshold and only 14 exceeded 10,000. The authors found evidence of an overspill from successful petitions to less successful ones; a positive fact which suggests that system use is reinforced. Starting from the observation that few users signed more than one or two petitions, the analysis of co-signing patterns can classify users into four types:

(1) "New Lobbyists" who consistently sign petitions in the same topics (less than 1\%).

(2) "Hit and Run Activists" who sign multiple non-related petitions in short periods of time (less than $1 \%$ ).

(3) “Activism Consumers" who over time sign multiple non-related petitions (about 16\%).

(4) "Single Issue Stakeholders" who signed maximum two petitions in non-related categories (almost 84\%).

- Lindner and Riehm (2011) presented the findings of a dual evaluation survey of 350 online and 571 traditional petitioners to the German Parliament. Existing bias in gender and socio-economic status were even amplified with online petitioners. In both groups, well-educated males are dominant and, furthermore, ePetitioners tend to be younger than traditional petitioners. Digital divide was not the reason why traditional petitioners did not select the online route: only $17 \%$ of them were aware of the option and $70 \%$ of them thought of this option as appealing. Both traditional and online petitioners are more politically engaged than the average population. Interestingly, while $76 \%$ of traditional petitioners were satisfied about the process, this drops to $42 \%$ for online petitioners, possibly due to the high rejection rates for publishing ePetitions.

\subsection{Petitioning the government}

While many parliaments are receiving or are considering receiving ePetitions, national governments have not been equally enthusiastic. A prominent exception is the UK Prime Minister's ePetitioning website which, since its launch in 2006, managed to attract millions of signatures in thousands different topics. Citizens could traditionally petition the government through the Prime Minister's office, but the online system came along with diverse opinions even within the Labour government. The government's ePetitions were terminated in 2010 by the newly elected government. 
Prior to this, the website managed to collect over 12,000,000 signatures in 33,058 different petitions; unarguably an indication of immense public interest which was enhanced by the initiative's location within the Prime Minister's website. Another 38263 petitions were rejected, most of them because they were duplicating existing ones or asking for an action outside the government's authority. The website was developed by mySociety (2011), a non-profit organisation which has launched many popular UK eDemocracy initiatives such as the TheyWorkForYou.com.

Petitions covered a great variety of topics, some of the most popular being: foreign affairs (e.g. European related-topics or the Iraq war), fuel prices, public expenses and honours suggestions. The website guaranteed a formal response to petitions gathering more than 200 signatures. How petitions were handled was not visible to the public in detail. Miller (2009) provides examples of petitions received by the website and the types of answers generated by the government's officials. In most cases, the response was a link to policy developments in progress. In other cases, the government responded positively to petitioners' suggestions or clearly explained why those suggestions could not be considered.

There are many examples of noteworthy petitions, such as the one asking the Prime minister to resign (over 72,000 signatures), the one to create a new public holiday (over 530,000 signatures) and the one to reduce fuel prices (over 304,000 signatures). The most remarkable case is the petition to "Scrap the planned vehicle tracking and road pricing policy" started by a citizen named Peter Roberts in early 2007 and signed by 1,811,423 others. Naturally, the petition found the government in an uncomfortable position, drew substantial media attention and came with debates over the broader relationship between Internet and politics.

This petition highlighted more any other the effects of technology on traditional participation activities. As Navarria (2010, p.18) comments: "In a short period of time, with as little organizational effort as possible and no financial commitment, a citizen with no previous experience in either politics or petitioning managed to achieve something unthinkable for any traditional petitioner in the same conditions". Furthermore, he informs that the government initially tried to minimise the petition's importance, but finally had to withdraw the road pricing proposal. The response by the Prime Minister, Tony Blair (2008), emphasised that despite not sharing the views of petitioners himself, the web indeed offered people the opportunity to generate a national debate in a few mouse clicks. Nevertheless, controversy over the usefulness and impact of ePetitions was intense even within the government (e.g. Navarria 2010).

This is probably one of the reasons why the coalition government decided to terminate the Prime Minister's ePetitions prior to its re-launch on the main governmental portal Direct.gov in the summer of 2011. The re-launch plan was part of the Conservative party 2010 elections manifesto and is based on a completely different concept which resembles the German Bundestag's paradigm (House of 
Commons 2011): only online petitions having 100,000 or more signatures are eligible for debate in the British Parliament.

Apparently, this change differs from the former Labour government's intention to provide an inclusive channel easily accessible by citizens and respond to petitions on a regular basis. On the other hand, it also hints that petitions which will collect that many signatures can actually receive considerable attention within the formal parliamentary processes. The re-launch plan estimates that the opportunity to debate a petition with the Westminster Parliament will draw considerable public attention even compared to the previous system (Skunkwork 2011). Administration to the new system will be flexible with a small team facilitating the connection between petitioners and government departments responding to petitions. Due to the high cost, no discussion forums or commenting facilities will be provided, but connections with social media are part of the official system's requirements (Skunkwork 2011).

This final aspect is quite motivating because, although there is no formal evaluation of citizens' views on government's ePetitions, some interesting observations have been made on how some those petitions were promoted through social networking groups. Panagiotopoulos et al. (2011b) collected and analysed more than 500 Facebook groups created for this purpose. The comparison between groups' memberships and the number of official signatures on the government's website revealed unpredictable relationships. There were many cases where popular issues generated significant activity in the social networking sphere which did not necessarily translate into petition signatures. It would be interesting to examine whether such patterns will occur with the new system where the high threshold require substantial campaigning probably in both offline and online media.

\subsection{Petitioning local authorities}

Participation in local government politics usually concerns everyday issues which are more easily understood by the public compared to more complicated national government affairs. This is a characteristic that potentially encourages people to petition local authorities, although it might also make such an activity unnecessary or too formal for some localised topics. In the UK, the increasing interest in local government ePetitioning led to a regulatory arrangement that eventually resulted in the implementation of more than 280 English local ePetitioning websites as of March 2011 (Panagiotopoulos et al. 2011a). Before elaborating on this, it is useful to trace the history of those efforts.

In 2004, the London Royal Borough of Kingston-upon-Thames and the Bristol City Council were the first to use online petitioning in parallel to their paper petitioning structures. Their pilot application was organised through their involvement with the Local eDemocracy National Project (2005) which examined a whole range of local eDemocracy tools (e.g. forums, citizen panels). The initial software adopted was the ePetitioner (as in the Scottish Parliament). Petitioning in Kingston 
and Bristol was already established since those two authorities belonged to the ones guarantying a response to petitions; according to a 2007 national survey less than a third of local authorities did so (Communities and Local Government 2008). More information about the Local eDemocracy National Project and the pilot evaluation of the two ePetitioning systems can be found in Whyte et al. (2005a, 2005b).

Hilton (2006) outlines the Bristol experience and particularly explains the transition from information and consultation to providing spaces for bottom-up participation such as ePetitions. According to the official statistics, since 2004, the Bristol system has handled more than 200 petitions which accumulated a total of almost 75,000 signatures in a population of about 433,000 (Bristol City Council 2011). A very influential example is a January 2008 petition that eventually managed to save a railway path from becoming a bus route. It was supported by more than 10,000 Bristol citizens.

Aiming to examine the impact of the initiative in local democratic processes, a detailed case study investigation was conducted with Kingston in the first six months of 2010 (Panagiotopoulos, Al-Debei 2010, Panagiotopoulos et al. in press). The positive impact of ePetitions was thought to be an outcome of two main facts: (1) the leading involvement by key stakeholders (councillors, local officers, community organisations) and (2) the application of a coherent response process to petitions regardless of their submission channel. Particularly the later linked the online space with existing decision making structures; those being the specialised council committees where petitions where debated and decided at the presence of petitioners. Furthermore, the system was beneficial in coordinating and enhancing the process, for example, in terms of supporting petitioners at the drafting stage, making all stages visible and adding background information on petitioning topics.

Following the positive experiences and widespread interest with the two pilot cases, more UK local authorities started experimenting with ePetitioning tools; to name a few: Lambeth, Birmingham and Brighton \& Hove. Quite a few UK companies started offering ePetitioning solutions to local authorities along with other democratic support systems (e.g. consultation portals, content management). Within this climate of general interest, in November 2009, the Labour government created a new legislation on a diverse set of issues around local government: the Local Democracy, Economic Development and Construction Act (2009).

According to the Act's second chapter, every authority in England "must provide a facility for making petitions in electronic form to the authority". It also had to decide on and apply an explicit response process for both paper and online petitions. Authorities were additionally required to clarify a series of issues such as: what they consider as a valid petition, what kind of actions a valid petition might trigger, how appeals to the process can be handled and so on. A more elaborate set of directions on implementing this duty was provided by consultation organised by the Communities and Local Government (2008). It is reasonable to note that certain details of this regulation were based on the 
experiences of early adopters and mainly Kingston and Bristol. The legislation was also inspired by the popularity of the government's petitioning system.

Certainly, the 2009 Act has been one of the very few cases where a particular eParticipation tool was regulatory enforced from the national to the local government. The deadline for the ePetitioning implementation was middle December 2010. Nevertheless, the new government was not equally enthusiastic about the concept and the way it fitted into its Big Society agenda (see introduction). This broader citizen empowerment plan sought to provide autonomy to local communities instead of directing them to specific decision making activities such as petitions. Effectively, in September 2010, the new government withdrew the guidance on the implementation of ePetitions and directed authorities' attention to the forthcoming Localism Bill (2010) for future plans. Yet, local authorities were asked to comply with the minimum legislative requirements for ePetitions. At that time, most authorities had already decided on the details of how to address them and, despite the political uncertainty, it is likely that most proceeded with their initial plans.

In March 2011, Panagiotopoulos et al. (2011a) visited all the 353 English local government websites and located an ePetitioning facility in over 280 of them. Although most authorities did launch ePetitions, only in limited cases they seemed to be promoting the initiative or having implemented innovative characteristics to their systems (e.g. connections to social networks, discussion forums). Another general observation was that those performing better in other eParticipation activities (e.g. consultations, webcasting) placed more effort to implement ePetitions and their systems were more used.

About $37 \%$ of those facilities were not easily visible within the councils' websites and, in about half, the levels of assistance and instructions to prospective users were more or less inadequate. Evidence of early adoption (systems in operation before December 2010) was found in less than $10 \%$ of the cases. The level of systems' use was not encouraging either: in more than $75 \%$ of local authorities there was not a single open or closed petition. The study also found that authorities did not attempt to set high signature thresholds for petitions to be considered. Many of them stated that they would consider petitions regardless of their signature volume or that they require up to 50 signatures. Finally, in line with the Act, authorities introduced different kinds of petitions: those asking for a full council debate on a topic or those to hold a public officer accountable. Different thresholds were set for those kinds of petitions (not investigated in the study).

Local government in the UK presents an interesting application field to examine the relationship between grassroots tools and institutional processes. Outside the UK, there are few developed experiences with local government petitioning. As informed by Lindner and Riehm (2009), in the period 2005-2007, 14 Norwegian municipalities participated in a pilot ePetitioning project. Public responses were not encouraging since a required 300 signature threshold proved to be a real barrier to the process (only two petitions met the requirement).

Figure 1 above summarises this review in the form of a timeline while table 1 groups some addresses of ePetitioning websites. 


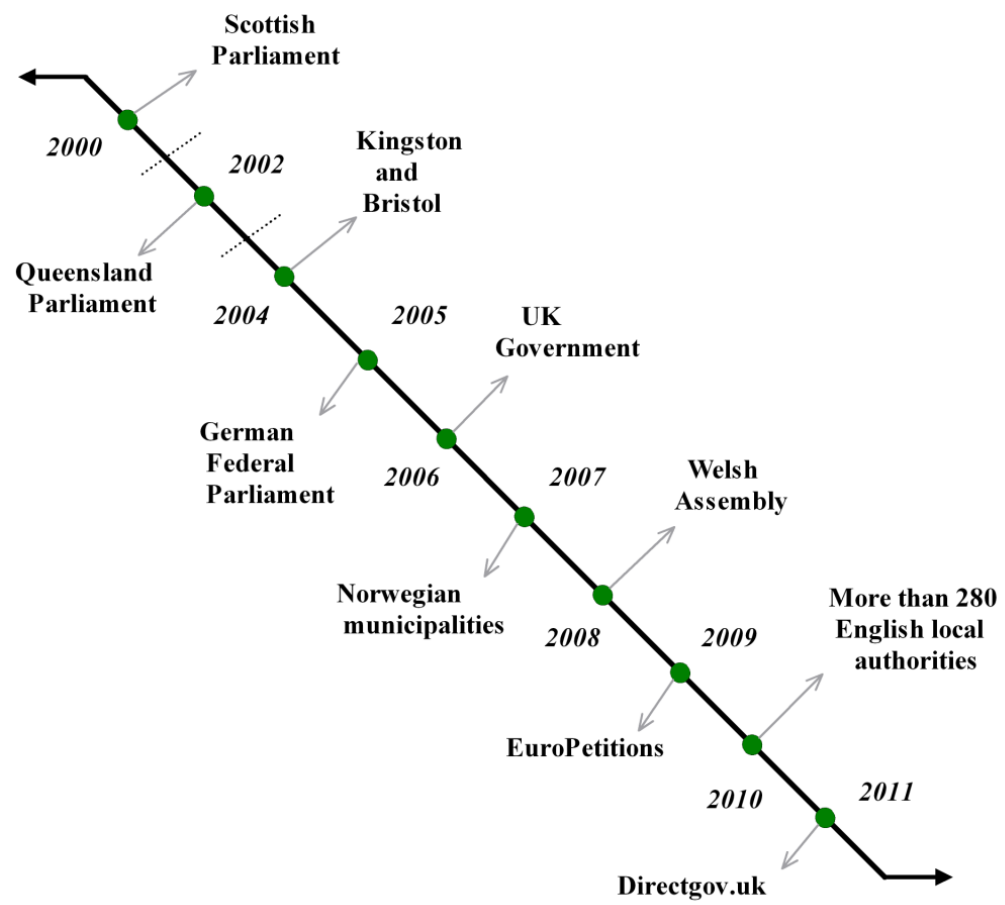

Figure 1: Timeline summarising the introduction of ePetitioning systems.

\section{On engagement from the grassroots}

Going back to the chapter's main question, the ePetitioning experiences reveal interesting characteristics about the proposition of high volume participation activities and their use as paths to influence policy making. The discussion first comments on public expectations with respect to traditional politics and then focuses on what we have learned about configuring such tools.

\begin{tabular}{|c|c|}
\hline Authority & Website \\
\hline Scottish Parliament & http://epetitions.scottish.parliament.uk/ \\
\hline German Parliament & https://epetitionen.bundestag.de/ \\
\hline UK Government & http://petitions.number10.gov.uk/ \\
\hline Welsh Assembly & $\frac{\text { http://www.assemblywales.org/gethome/e- }}{\text { petitions.htm }}$ \\
\hline Queensland Parliament & http://www.parliament.qld.gov.au/view/EPetitions_QLD \\
\hline EuroPetitions in Spain & http://www.europetitionandalucia.es/epetition core/ \\
\hline $\begin{array}{l}\text { EuroPetitions in } \\
\text { Sweden }\end{array}$ & http://europaforslag.se/epetition_core/ \\
\hline Kingston upon Thames & http://epetition.kingston.public-i.tv/epetition_core/ \\
\hline
\end{tabular}




\section{Bristol City Council http://epetitions.bristol.gov.uk/epetition core/}

Table 1: Examples of ePetitioning websites used by authorities (accessed 25/05/2011).

\subsection{Balancing expectations and widening the scope}

EPetitions seem to adapt quite well to the main challenges of online engagement as outlined by Macintosh (2004) 1. First of all, they are not usually affected by the participation scale. With the exception of the different thresholds applied in the English local government, in the other cases all petitions collecting a certain minimum of signatures trigger the same response process. Next, ePetitions can be combined with many additional tools to support and contextualise the participation process, for example social networks, links to support material and discussion forums. Furthermore, ePetitions have a clear position in the policy making lifecycle: they address the agenda setting and evaluation stages. Finally, they can be evaluated from different qualitative and quantitative perspectives; the studies presented at the end of section 2.1 are indicative of how informative such evaluations can be.

However, it seems that good fit with fundamental challenges does not guarantee either public acceptance or sustainable participation. Reflecting on the ePetitioning experiences, it is useful to see if high-volume tools can indeed increase and widen the scope of traditional participation. Where online and paper petitions were introduced at the same time (e.g. Welsh Assembly and Scottish Parliament), it is difficult to explore the differences. In the German Parliament, ePetitions did contribute to increasing the total number of petitions and signatures. Yet, it that case, there also was a parallel element of procedural innovation since petitions were not discussed in public at all before 2005. In the UK local authorities, the long term experiences of Kingston and Bristol do not show a considerable increase in the number of petitions. In fact, paper petitions have always remained the majority in Kingston, especially the ones about more localised topics.

Paradoxically, the UK government's system seems to be the only case where, compared to the traditional process, the online activity came along with an indisputable increase in the number of petitions and their signature volumes. From this point of view, this ambiguous and very popular initiative can be considered the flagship of high-volume engagement. Surprisingly, its popularity resulted in neither the government nor the public being absolutely satisfied by its existence. The topics and unexpected use of petitions imply that in some cases the website was used more to provoke the government than to achieve genuine participation.

For example, in many cases debate about the system evolved around the question of whether the government is actually listening or at least appears to be listening. Normally, within the government

\footnotetext{
${ }^{1}$ In brief, those are: (1) handling the engagement scale, (2) enhancing citizens' capacity to contextualise their participation, (3) ensuring coherence within the policy making lifecycles, (4) understanding the role of evaluation and (5) demonstrating commitment by involved actors.
} 
they gradually felt that they had more to lose than gain from engaging with the public in this way; such conclusions for elected representatives are not novel in digital governance research (e.g. Mahrer, Krimmer 2005). Hence, as Navarria (2010) explains, high volume tools present remarkable opportunities to enhance representative relationships, but can also threaten the representative system if used in populist ways.

There are two possible reasons why only the UK government's ePetitions so intensively reached that point. The first is the expected high visibility and wider media attention of an initiative organised by the Prime Minister's office. Traditionally, UK national petitions have been delivered to the Government at 10 Downing Street rather than the Speaker at the Houses of Parliament. The second is that participation required the least possible effort: users just added their name on a single declaration issue summarised in a few lines to receive an answer from the government's officials some days or even hours later. In contrast, most petitions in local authorities such as Kingston and Bristol came along with wider debates and were publicly discussed and decided in specialised council committees.

Overall, in the ePetitioning cases, we have no evidence that citizens felt that their experience influenced their perceptions of politics positively. In contrast, Carman's (2010) study revealed a negative relationship between perceptions of procedural fairness and opinions about the political system itself. It is not surprising to see that matching the experimental use of those tools with considerable public expectations is inevitably challenging and more process-oriented. As stated by Seaton (2005, p. 337): "not every petitioner is satisfied by the outcome of their petition, but people appreciate that it has been given serious consideration".

Furthermore, from the ePetitioning experiences, it is difficult to notice that the scope of politics was expanded with citizens who are traditionally disengaged. The analysis by Jungherr and Jürgens (2010) provides evidence that popular petitions attract wider system use, but very few users exhibit patterns of informed political behaviour, for example by signing petitions around the same topic(s) over time. The survey by Lindner and Riehm (2011) further shows that, with the exception of younger citizens, participation biases were amplified with the online process. This survey seems to confirm other studies which highlight the dominance of Internet skills in online participation activities and eventually the socio-economic factors that determine them (e.g. gender, education and income) (Krueger 2006, Best, Krueger 2005).

Therefore, it is difficult to conclude that high volume tools can widen the scope of traditional participation. However, the richness of petitioning topics and the public support attracted in all cases is certainly promising. The different ways in which those ePetitions have been integrated in political contexts provides useful lessons about the configuration of high volume tools. 


\subsection{Integrating high volume tools}

High volume tools such as petitions are useful for authorities as assistance for prioritising actions, consulting a wide spectrum of stakeholders and identifying citizen feedback on key policy issues. Integration into an engagement strategy can be the guiding principle for configuring their proposition. The ePetitioning review confirms that those tools are of little value as isolated systems and need to be complemented by other forms of deeper engagement. In general, government-driven deliberation activities on the web tend to be disconnected with political processes (Rose, Saebo 2010). This is not unexpected for many reasons; some of which might be the rapid pace of technological change and the limited knowledge of citizens' expectations which hinder the adaptation of formal politics.

Even with activities such as petitions where the topics are clearly decided by citizens, it is still the authority that determines the quality of the process by supporting its strategy for informed engagement. For example, authorities could look at the experiences of political mobilisation groups which combine petitions with more targeted activities (Karpf 2010). Their advanced and combinatory tactics in many cases go beyond the phenomenon of political "clicktivism" where massive engagement tools are used to educate the public about issues of interest, encourage them to take easy and small steps and then try to engage them in more significant follow-up tasks. There is little evidence that authorities have managed to connect their engagement efforts in similar escalating logics that can reach people according to their availability and willingness to participate.

In turn, the limited integration of high volume activities often results in them being criticised for their inherent deliberation gap which one or way or another needs to be taken into account when planning their use. For example, the Scottish and the German Parliament are trying to cover this gap by operating discussion forums for petitions. Other examples observed in the English local government include mailing lists, commenting facilities and even voting options (Panagiotopoulos et al. 2011a). Providing spaces for discussion is also related to enhancing petitioners' dissemination ability. Petition campaigning is not the authority's responsibility, but is certainly an element that can't be overlooked in order to build a sustainable participation process inclusive to normal citizens who don't possess organised promotion mechanisms.

Apart from campaigning, supporting petitioners is necessary at all stages and should be provided on a regular basis. For example, in the Kingston case study, it was obvious that proactiveness in drafting petitions helped to address topics within the authority's power and also accelerated the process. Emphasis on the clarity of the process seems to be an important element of all the systems used by parliaments and local authorities. Petitioning stages are published on the web including the petition response. Apart from transparency, this element increases the visibility of the process and its comprehension by the public. It also facilitates connections with other online material which enhance integration. 
In any case, it should not be taken for granted that existing mechanisms for participation can integrate high volume activities. For example, petitions require that authorities are able to regularly respond to all policy making topics and organise a fair and coherent response process. Carman's (2010) study, apart from highlighting the importance of perceptions of political fairness, also brings to attention the fragile balance between the public and those administrating the public's input. In many cases and especially in the German one, it was evident that the Petitions Committee has significant influence over the process as it could decide on which petitions were suitable enough to become public. The public's disapproval of this administrative power was reflected in the evaluation results (Lindner, Riehm 2011).

Therefore, the ePetitioning experiences indicate that, apart from the technical issues, how the process is communicated to the public matters and bears attention. It is critical to establish the political and support structure behind the website so that processes are transparent, easy to understand and use and citizens feel they get a fair hearing. Furthermore, technical issues cannot be overlooked, with authentication of signatures being a matter of increasing concern, especially in cases where different signature thresholds can trigger different actions.

\section{Concluding remarks}

This chapter discussed the extent to which high volume engagement tools can be consistently used by public authorities as a response to citizens' preference for bottom-up participation. The integrated ePetitioning experiences with parliaments, national and local governments are mostly positive, but do not seem to provide solid evidence about significant impact achieved. Yet, they do point that such activities are popular amongst Internet users and some of those systems can now be considered institutionalised forms of politics instead of "innovation in progress". For example, the Scottish Parliament has completed over a decade of ePetitioning and many other authorities have exceeded five years.

Undoubtedly, the uptake of high volume tools is not yet massive and there is long way for contemporary politics to become more compatible with the Internet philosophy of open collaboration. New activities such as crowdsourcing and social networking offer noteworthy participation opportunities and open unexplored directions for authorities that seek to improve feedback from their public. Nevertheless, citizens' use of networking tools for political mobilisation outside the boundaries of existing institutions should not assume that they will be equally keen to contribute to formal politics. There is certainly debate to come about the implications of those new phenomena and the challenge of enacting engagement from the grassroots. 


\section{References}

Best, S.J. \& Krueger, B.S. (2005) Analyzing the representativeness of Internet political participation", Political Behavior, 27:183-216.

Blair, T. 2008, 15/1-last update, The E-Petition Shows that my Government is Listening [Homepage of guardian.co.uk], [Online]. Available: http://www.guardian.co.uk/commentisfree/2007/feb/18/uk.transport [2009, 20/11].

Bristol City Council 2011, Bristol petitions. Available: http://www.bristol.gov.uk/ccm/navigation/council-and-democracy/consultations/petitions/ [2011, 15/05].

Cabinet Office 2011, Big Society - overview. Available: http://www.cabinetoffice.gov.uk/content/bigsociety-overview [2011, 15/05].

Carman, C. (2010), "The Process is the Reality: Perceptions of Procedural Fairness and Participatory Democracy", Political Studies, 58:731-751.

Communities and Local Government 2008, 28/7-last update, Local Petitions and Calls for Action Consultation: Government Response [Homepage of Department for Communities and Local Government], [Online]. Available: http://www.communities.gov.uk/documents/localgovernment/pdf/906840.pdf [2010, 20/02].

Cruickshank, P. \& Smith, C. (2011a), EuroPetition Monitoring and Evaluation Report, EuroPetition project.

Cruickshank, P. \& Smith, C. (2011b), "Understanding the "E-Petitioner"', Transforming Government: People, Process and Policy, vol. in press.

Dutton, W.H. \& Eynon, R. (2009), "Networked Individuals and Institutions: A Cross-Sector Comparative Perspective on Patterns and Strategies in Government and Research", The Information Society, 25:198-207.

Dutton, W. \& Helsper, E.J. (2007), The Internet in Britain: 2007, Oxford Internet Institute, University of Oxford, Oxford, UK.

Dutton, W.H. (2009), "The Fifth Estate Emerging through the Network of Networks", Prometheus, vol. 27:1-15.

Dutton, W.H., Helsper, E.J. \& Gerber, M.M. (2009), The Internet in Britain: 2009, Oxford Internet Institute, University of Oxford.

Garrett, R.K. (2006), "Protest in an Information Society: a Review of Literature on Social Movements and New ICTs", Information, Communication \& Society, 9:202-224.

Hilton, S. (2006), "Developing Local E-Democracy in Bristol: From Information to Consultation to Participation and Beyond", Aslib Proceedings, 58:416-428.

House of Commons (2011), Proposals for debating petitions and for a public reading stage for bills [Homepage of House of Commons], [Online]. Available: www.parliament.uk/briefingpapers/SN05884.pdf [2011, 25/05].

Jungherr, A. \& Jürgens, P. (2010), "The Political Click: Political Participation through E-Petitions in Germany", Policy \& Internet, 2:131-165.

Karpf, D. (2010), "Online Political Mobilization from the Advocacy Group's Perspective: Looking Beyond Clicktivism", Policy \& Internet, 2:7-41.

Krueger, B.S. (2006), "A Comparison of Conventional and Internet Political Mobilization", American Politics Research, 34:759-776. 
Lindner, R. \& Riehm, U. (2011), "Broadening Participation Through E-Petitions? An Empirical Study of Petitions to the German Parliament", Policy \& Internet, 3:1-23.

Lindner, R. \& Riehm, U. (2009), "Electronic Petitions and Institutional Modernization. International Parliamentary E-Petition Systems in Comparative Perspective", eJournal of eDemocracy and Open Government, 1:1-11.

Local Democracy, Economic Development and Construction Act (2009), 12/11-last update [Homepage of Office of Public Sector Information], [Online]. Available: http://www.opsi.gov.uk/acts/acts2009/ukpga_20090020_en_1 [15/9, 2010].

Local E-Democracy National Project (2005), Barriers to E-Democracy: Local Government Experiences and Responses, Local E-Democracy National Project.

Localism Bill 2010, 13/12-last update, Localism Bill starts a new era of people power [Homepage of Communities and Local Government], [Online]. Available: http://www.communities.gov.uk/news/newsroom/1794971 [2010, 29/12].

Macintosh, A. (2004), "Using Information and Communication Technologies to Enhance Citizen Engagement in the Policy Process" in Promise and Problems of eDemocracy: Challenges of Online Citizen Engagement, eds. J. Caddy \& C. Vergez, OECD, pp. 19-142.

Macintosh, A., Malina, A. \& Farrell, S. (2002), "Digital Democracy through Electronic Petitioning" in Advances in Digital Government, eds. W.J. McIver \& A.K. Elmagarmid, Springer US, , pp. 137-148.

Mahrer, H. \& Krimmer, R. (2005), "Towards the Enhancement of E-Democracy: Identifying the Notion of the 'Middleman Paradox'", Information Systems Journal, 15:27-42.

Miller, L. (2009), "E-Petitions at Westminster: the Way Forward for Democracy?", Parliamentary affairs, 62:162-178.

Misuraca, G.et al. (2011), Envisioning Digital Europe 2030: Scenarios for ICT in Future Governance and Policy Modelling, European Commission, JRC, Spain.

mySociety (2011), [Homepage of mySociety], [Online]. Available: http://www.mysociety.org/about/ [2011, 15/05].

National Assembly for Wales (2011), Petitioning: bringing your issues to light, National Assembly for Wales, Petitions Committee.

Navarria, G. (2010), "The Internet and Representative Democracy: a Doomed Marriage?", Internet, Policy and Politics 2010: an Impact Assessment, St Anne's College, University of Oxford 16-17 September 2010.

Panagiotopoulos, P. \& Al-Debei, M.M. (2010), "Engaging with Citizens Online: Understanding the Role of ePetitioning in Local Government Democracy", Internet, Politics, Policy 2010: An Impact Assessment, St Anne's College, University of Oxford 16-17 September 2010.

Panagiotopoulos, P., Moody, C. \& Elliman, T. (2011a), "An Overview Assessment of ePetitioning Tools in the English Local Government", (eds) Tambouris, E., Macintosh, A. \& de Bruijn, H., 3rd International Conference on eParticipation, LNCS 6847, pp. 204-215.

Panagiotopoulos, P., Sams, S., Elliman, T. \& Fitzgerald, G. (2011b), "Do Social Networking Groups Support Online Petitions?", Transforming Government: People, Process and Policy, 5:20-31.

Panagiotopoulos, P., Al-Debei, M.M., Fitzgerald, G. \& Elliman, T. (in press), "A Business Model Perspective for ICTs in Public Engagement", Government Information Quarterly.

Rose, J. \& Saebo, O. (2010), "Designing Deliberation Systems", The Information Society, 26: 228240. 
Saebo, O., Rose, J. \& Flak, L.S. (2008), "The Shape of eParticipation: Characterizing an Emerging Research Area", Government Information Quarterly, 25:400-428.

Scottish Parliament (2011), The Scottish Parliament ePetitions. Available: http://epetitions.scottish.parliament.uk/ [2011, 15/05].

Seaton, J. (2005), "The Scottish Parliament and E-Democracy", Aslib Proceedings, 57:333-337.

Shulman, S.W. (2009), "The Case Against Mass E-mails: Perverse Incentives and Low Quality Public Participation in U.S. Federal Rulemaking", Policy \& Internet, 1.

Skunkwork (2011), E-Petitions Revised Proposal for Directgov, Skunkwork HM Government.

Whyte, A., Renton, A. \& Macintosh, A. (2005a), eDemocracy from the Top Down: An Evaluation of eDemocracy Activities Initiated by Councils and Government, Bristol City Council for The Local eDemocracy National Project.

Whyte, A., Renton, A. \& Macintosh, A. (2005b), e-Petitioning in Kingston and Bristol: Evaluation of e-Petitioning in the Local e-Democracy National Project, Napier University. 